\title{
K. GAJDOŠOVÁ, J. BILČíK
}

\section{SLENDER REINFORCED CONCRETE COLUMNS STRENGTHENED WITH FIBRE REINFORCED POLYMERS}

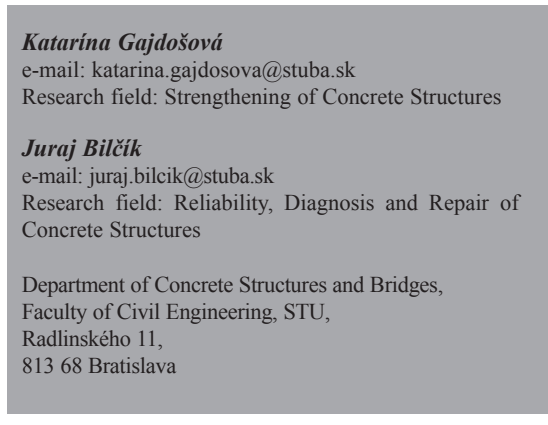

Katarína Gajdošová

Juraj Bilčí

-mail: juraj.bilcik@stuba.s

Research field: Reliability, Diagnosis and Repair of

ures and Bridges,

Faculty of Civil Engineering, STU,

81368 Bratislava

\begin{abstract}
The requirement for a long life with relatively low maintenance costs relates to the use of building structures. Even though the structure is correctly designed, constructed and maintained, the need for extensions of its lifetime can appear. The preservation of the original structure with a higher level of resistance or reliability is enabled by strengthening. Conventional materials are replaced by progressive composites - mainly carbon fibre reinforced polymers (CFRP). They are used for strengthening reinforced concrete columns in two ways: added reinforcement in the form of CFRP strips in grooves or CFRP sheet confinement and eventually their combination. This paper presents the effect of the mentioned strengthening methods on slender reinforced concrete columns.
\end{abstract}

\section{KEY WORDS}

- strengthening

- slender concrete columns,

- fibre reinforced polymers,

- CFRP sheet,

- CFRP strips.

\section{INTRODUCTION}

The design of slender load-bearing members is the most asserted trend today. The same requirement is then imposed on strengthened structures and members. That is the main reason for replacing strengthening techniques using conventional materials (concrete, steel) with new ones. Progressive composites - fibre reinforced polymers (FRP) - have many advantages such as high strength-toweight and stiffness-to-weight ratios, corrosion resistance, ease of installation, etc.; their disadvantage is their relatively high cost. For static strengthening purposes, unidirectional composites with carbon fibres and epoxy resin are the most widely used.

There are two forms of carbon fibre reinforced polymers used for strengthening. Polymers in strip form are bonded to the structural member's surface or into the pre-cut grooves in the concrete cover - the well-known near surface mounted reinforcement method (NSMR). They transfer tensile forces and perform as added reinforcement with related characteristics. Polymer sheets in a confinement form can be shaped like stirrups or continuously like a spiral. The confinement effect is based on the well-known fact that the containment of the lateral deformation of concrete increases its strength. The confinement effects can be considered by the increase in the concrete's strength and the modification of the stress-strain model.

The confinement of concrete has a major effect on columns - its effect on axially loaded short squared and circular concrete columns has been demonstrated in numerous tests (also Olivová (2007)). The research on eccentrically loaded slender concrete columns is still quite limited, and there are few publications on this topic, which is why this application is not advanced.

Mirmiran, et al. (2001) started the research in this field with concrete-filled fibre-reinforced polymer tubes (CFFT), which 
showed that as the slenderness ratio is increased, the columns' strength rapidly drops [1]. Pan, et al. (2007) and Tao and Han (2007) investigated slender reinforced concrete columns wrapped with FRP; the behaviour of these columns differs from that of CFFTs, even though the strengthening effect decreases with an increase in the slenderness ratio and the initial end eccentricity [2], [3].

Confinement with a unidirectional and also a bidirectional CFRP jacket was the subject of Tao's and Yu's (2008) investigation. The ultimate strength measured for the columns (slenderness of about 70) strengthened by unidirectional CFRP is quite close to that of unstrengthened ones. The longitudinal fibres become more effective when bending becomes predominant [4]. A small-scale test of Fitzwilliam and Bisby (2010) contained columns wrapped with CFRP in a hoop and also in a longitudinal direction. For slender columns, wrapping in a hoop direction resulted in only a modest increase in capacity. Longitudinal CFRP wraps improve the behaviour of slender concrete columns and allow for the achievement of higher strengths and capacities [5].

To enable a wider application of strengthening techniques for slender concrete columns, it is necessary to engage in more research in this field and try to derive design methods for the strengthening effects of CFRPs.

\section{EXPERIMENTAL INVESTIGATION}

In order to assess the effectiveness of the CFRP laminate strips in the grooves method and wrapping with a CFRP sheet for strengthening slender concrete columns submitted to an eccentric compression load, four series of specimens were tested. The specimens were compounded of $4 \mathrm{~m}$ long columns, with a cross section of $150 \times 210$ $\mathrm{mm}$ and reinforced with a $2 \times 4 \phi 10$ hinge supported at both ends (Fig. 1). The first series consisted of non-strengthened columns; the second series was composed of concrete columns strengthened with CFRP laminate strips in the grooves; the third series was composed of columns confined with a CFRP sheet; and the last series was composed of columns strengthened with a combination of these methods.

All the columns were loaded in the same way - the compression force acted on the initial eccentricity of $40 \mathrm{~mm}$, and its value grew in ten loading steps to the resistance force expected from the theoretical analysis. The experimental test set-up is shown in Fig. 2. Strains of the concrete, steel and composite reinforcements and deflection from the increasing bending moment at the mid height were monitored during the increase in the compression force.

The observation of the relationship between the deflection at the mid height and the eccentrically acting compression force was the prime objective of the experimental investigation. The most accurate

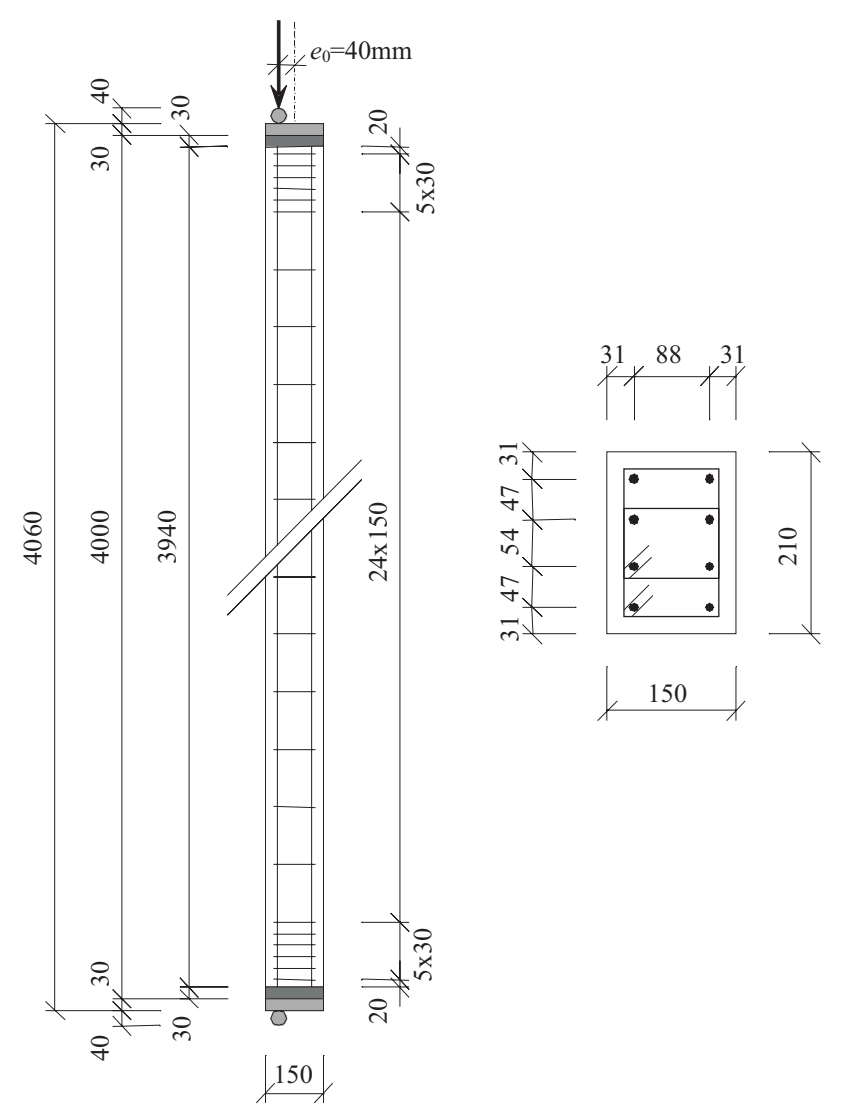

Fig. 1 Geometry, reinforcement and fitting of a column.

measurement allowing for descending branch plotting was enabled by linear variable displacement transducers (LVDTs) - Fig. 3. The increase in the resistance of the compression force beside the non-strengthened reinforced concrete column can be estimated as follows: $12.9 \%$ for the columns strengthened by adding the CFRP strips into the grooves in the concrete cover layer; $2.4 \%$ for the columns strengthened by confinement with one layer of the CFRP sheet; $15.4 \%$ for the columns strengthened by a combination of CFRP strips and a CFRP sheet. These main measurements show good agreement with the check scaling (direct: theodolite and indirect: tensometers, deformeters). The indirect measurements allow for calculating the final deflection of the most stressed crosssection from the strains measured. Strains of the concrete, steel reinforcement and composite materials were observed.

From a comparison of the steel reinforcement and CFRP laminate strips and the tension and compression strains in the column strengthened by adding CFRP strips into the grooves in the concrete cover, it can be seen that the CFRP strip strains always have higher 


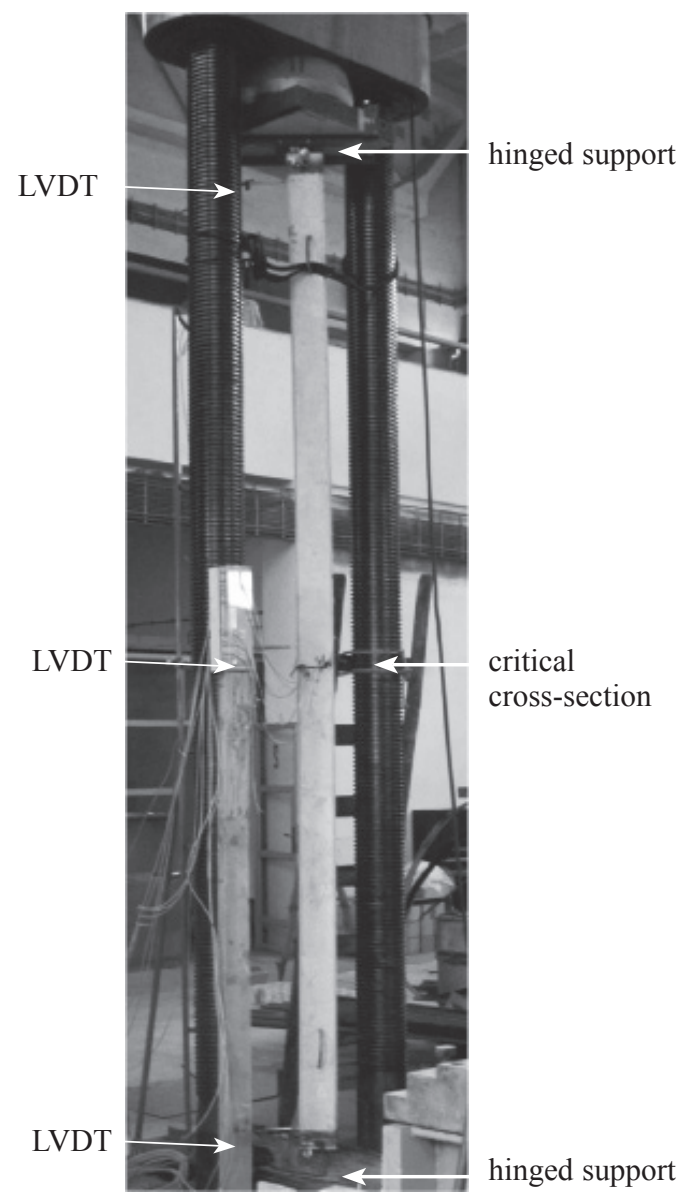

Fig. 2 Set-up of the experimental test.

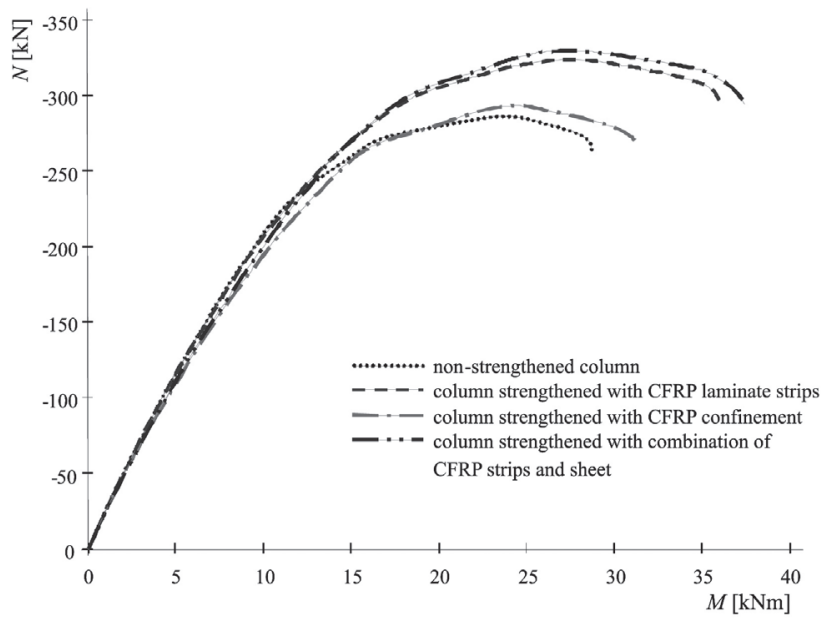

Fig. 3 Relation between the axial force and bending moment results from the LVDT measurements. values, which result from their greater distance from the neutral axis. The rupture of the CFRP strips was observed at the ultimate strain of $2.5-2.8 \%$. Similar values were measured by Olivová (2007) [6], which was five times less than the values from the tension test, which can be caused by another type of stress: there is a large curvature in the most stressed cross-section of the column, and the strip is not stressed in pure tension as during the tension test but in something like direct and bending stress. That is why the utilization of the strain capacity of CFRP strips is limited.

The measured values of the CFRP sheet strains in the columns strengthened with the CFRP sheet confinement were very low almost zero on the compressed face and a maximal $0.1 \%$ on the tensile face of the column's cross-section. The same values are listed in Tao and Yu (2008) [4]. These low strain values in the CFRP sheet led to a limited confinement effect - the necessary increase in the concrete' strength was not achieved.

\section{THEORETICAL AND NUMERICAL ANALYSIS}

Along with the experimental investigation, numerical modelling was executed; the ATENA 3D program was used. The material properties and static actions were adapted from full-scale tests. The numerical and experimental procedures give equivalent results. It was demonstrated that strengthening with CFRP strips in grooves is a more effective method for slender reinforced concrete columns. A theoretical analysis was carried out before testing the columns with the material properties measured according to a number of analytical models from sources abroad and then modified following the results of the experimental investigation. The models that mostly approximate the experimental results are further recommended for ordinary use.

The theoretical analysis consists of two parts. At first the resistance of a short column represented by a cross-section interaction diagram (ID) is constructed. In the second part, this diagram can be turned into a column interaction diagram to determine the resistance of a slender column without the additional second order effects. For the dimensions of the known column's cross-section, the material properties, slenderness and end eccentricity, the resistance axial force $N_{\mathrm{R}}$ can be taken from the column interaction diagram from the linear dependence of the axial force $N$ and the first order bending moment $M_{\mathrm{R}, 0}$. In a critical cross-section, the axial force $N_{\mathrm{R}}$ and total bending moment $M_{\mathrm{R}}$ (denoting the sum of the first order moment $M_{\mathrm{R}, 0}$ and the second order moment $M_{\mathrm{R}, \mathrm{II}}$ ) act (see Fig. 4).

For the ordinary use of the mentioned strengthening techniques, it is necessary to derive the method of the CFRP materials' inclusive effect on the section and column capacity. When calculating the strengthening effect, the CFRP strips in grooves can be included 


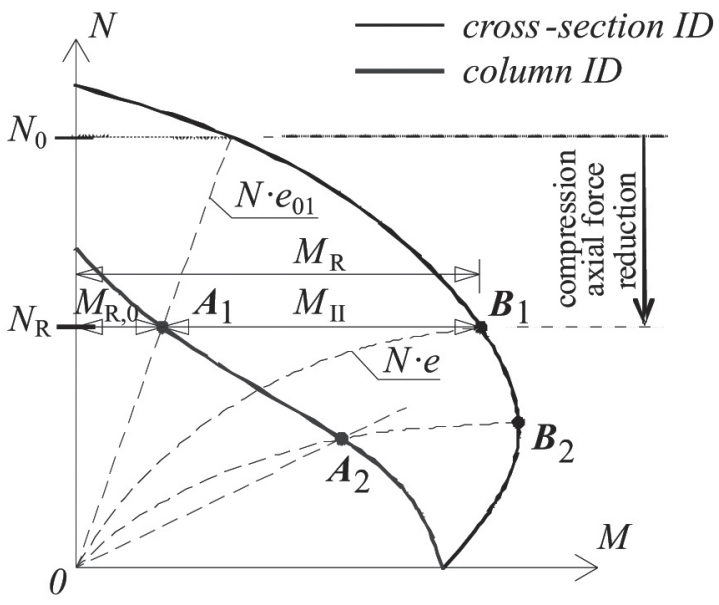

Fig. 4 Interaction diagram of slender column.

as an additional reinforcement near the cross-section's surface; the values of their strains are determined based upon the concrete strains, which depend on their distance from the neutral axis. Following the strain values of the CFRP strips, stress is determined from the linear stress-strain relation. It is very important to make provision for the initial strains in the reinforced concrete section when the CFRP strips are applied; during strengthening the structure is maximally relieved even though there are some low strains in the concrete and steel reinforcement, and it is necessary to calculate with them.

CFRP sheet confinement can be included as an increasing concrete strength and modified stress-strain relation. Lam and Teng's stress-

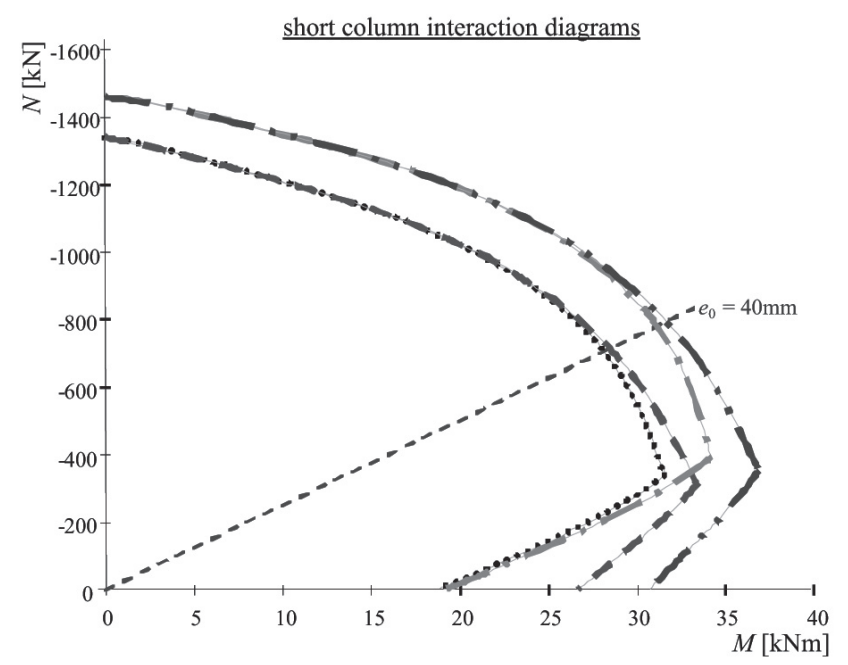

strain model (2003) [7] mostly approximates the experimental results. This diagram consists of a parabolic part followed by a linear part that ends at a point defined by the confined concrete's strength and ultimate strain. These values are calculated according to Teng (2007) [7]. The confined concrete's final stress and strain result from the confining pressure provided by the CFRP jacket, which depends on many factors that provision has to be made for. The most important factors are: the material properties of the CFRP sheet, the shape of the cross-section, the diameter of the rounded edges, and the continuous or stirrup-form confinement. Because of the linear $\sigma-\varepsilon$ diagram of the CFRP materials, the confining pressure continuously increases with the increasing strains of the CFRP sheet. The confinement's effectiveness is highly dependent on these strains.

A comparison of the short (cross-section ID) and slender column interaction diagrams of the four series of specimens is shown in Fig. 5: As a result of the interaction diagrams, the effect of the strengthening techniques is different for short and slender columns.

\section{CONCLUSIONS}

The results of all three investigations presented indicate that strengthening columns with the use of fibre reinforced polymers allows for an increase in load-carrying capacity without a significant increase in a cross-section.

The evident difference in the effect of strengthening techniques on the short and slender reinforced concrete columns is especially conclusive from the theoretical analysis. As a result of the short

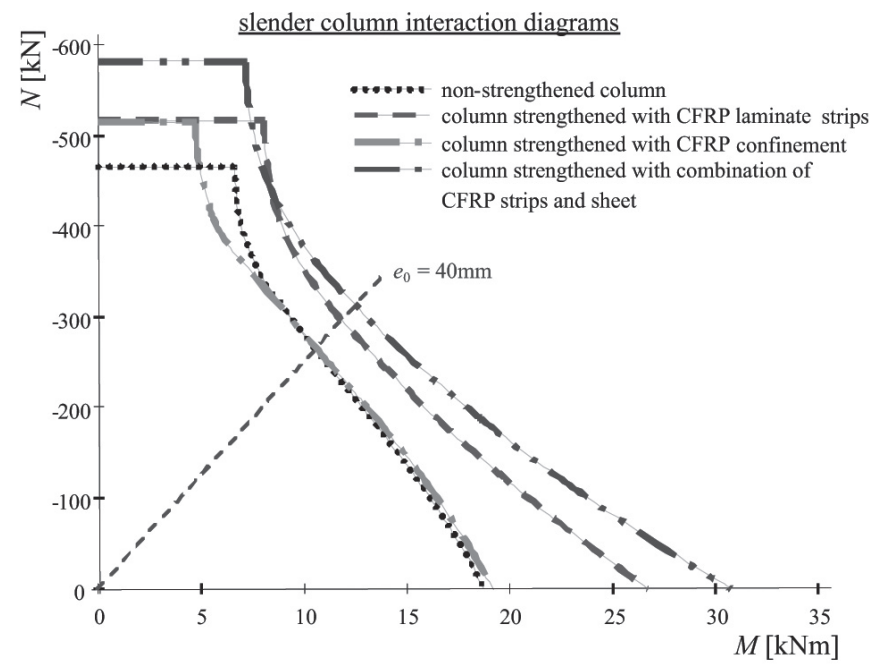

Fig. 5 Comparison of short and slender column interaction diagrams. 
columns' interaction diagrams (cross-section ID), the increase in load-carrying capacity is $1.3 \%$ for columns strengthened by near surface mounted CFRP strips, $10.8 \%$ for columns strengthened by confinement with a CFRP sheet, and $12.6 \%$ for a combination of these two methods. For slender columns, where provision is made for slenderness, the average increase in the resistance compression force beside a non-strengthened reinforced concrete column can be estimated as follows: $11.4 \%$ for columns strengthened by adding CFRP strips into the grooves in the concrete cover layer; $1.8 \%$ for columns strengthened by confinement with one layer of the CFRP sheet; $15.3 \%$ for columns strengthened by a combination of CFRP strips in the grooves and confinement with one layer of the CFRP sheet.

Generally it can be said that the most effective strengthening method depends on the predominant type of stress. The confined concrete would be most active in the case of compressive stress; longitudinal strains activate transverse strains and increase the confinement effect. The predominant compressive stress is assumed for short columns, which is why confinement by a CFRP sheet has a markedly higher effect on a short column's resistance. When calculating a strengthening action, CFRP sheet confinement can be included to increase the concrete's strength. CFRP strips act most efficiently if they are in tension; this case occurs on the tension side of a cross-section of a column strengthened with CFRP laminate strips in longitudinal grooves in a concrete cover along a column's axis. The type of stress is removed to the predominant bending region by slender columns, where the second order effects cause an increase in the bending moment at the same value of the compressive force. CFRP strips in grooves have a greater effect on the resistance of a slender column. For calculating strengthening actions, CFRP strips in grooves can be included as an additional reinforcement with related material properties.

\section{Acknowledgement}

This research was developed within and with the support of research project VEGA No. 1/0306/09 Application of Probabilistic Methods to Improve the Reliability of Concrete Structures.

\section{REFERENCES}

[1] Mirmiran, A., Shahawy, M., Beitleman, T.: Slenderness Limit for Hybrid FRP-Concrete Columns. In: Journal of Composites for Construction, Vol. 5, 2001, No. 1, pp. 26-34.

[2] Pan, J. L., Xu, T., Hu, Z. J.: Experimental Investigation of Load Carrying Capacity of the Slender Reinforced Concrete Column Wrapped with FRP. In: Construction and Building Materials, Vol. 21, 2007, No. 11, pp. 1991 - 1996.

[3] Tao, Z., Han, L. H.: Behaviour of Fire-Exposed Concrete-Filled Steel Tubular Beam Columns Repaired with CFRP Wraps. In: Thin-Walled Structures, Vol. 45, 2007, No.1, pp. 63 -76.

[4] Tao, Z., Yu, Q.: Behaviour of CFRP-strengthened Slender Square RC Columns. In: Magazine of Concrete Research, Vol. 60, 2008, No. 7, pp. $523-533$.
[5] Fitzwilliam, J., Bisby, L. A.: Slenderness Effects on Circular CFRP Confined Reinforced Concrete Columns. In: Journal of Composites for Construction, Vol. 14, 2010, No. 3, pp. $280-$ 288.

[6] Olivová, K.: Zosilňovanie betónových stĺpov lamelami a tkaninou z uhlíkových vlákien : Dizertačná práca (Strengthening of concrete columns with the use of carbon fibre polymer laminate strips and sheet : Dissertation thesis). Bratislava: Slovak University of Technology, 2007, 207 pp. (in Slovak)

[7] Hollaway, L.C., Teng, J.G.: Strengthening and rehabilitation of civil infrastructures using fibre-reinforced polymer (FRP) composites. Cambridge : Woodhead Publishing, 2008, 416 pp. 